\title{
BIOASSAY DATA FOR MARINE POLLUTION USING SEA URCHIN EGGS, 1970
}

AUTHOR(S):

Kobayashi, Naomasa

\section{CITATION:}

Kobayashi, Naomasa. BIOASSAY DATA FOR MARINE POLLUTION USING SEA URCHIN EGGS, 1970. PUBLICATIONS OF THE SETO MARINE BIOLOGICAL LABORATORY 1971, 18(6): 421-424

\section{ISSUE DATE:}

1971-03-31

URL:

http://hdl.handle.net/2433/175648

RIGHT: 


\section{BIOASSAY DATA FOR MARINE POLLUTION USING SEA URCHIN EGGS, 1970}

In 1970, nine experiments for biological assay were made using sea urchin eggs to measure marine pollution around the Seto Marine Biological Laboratory.

I. Winter season, February 21-22. Eggs of Hemicentrotus pulcherrimus (A. AgAssiz) were used (see Publ. Seto Mar. Biol. Lab., vol. 18, no. 6, p. 385, Table 1).

II. Spring season, May 21-22. Eggs of Anthocidaris crassispina (A. Agassiz) were used (see Publ. Seto Mar. Biol. Lab., vol. 18, no. 6, p. 386, Table 2).

III. Summer season, five experiments were made in June-August, using Anthocidaris crassispina eggs.

1. June 6-7, see Table 1 .

2. July 17 , see Table 2 .

3. July 21 (see Publ. Seto Mar. Biol. Lab., vol. 18, no. 6, p. 387, Table 3).

4. August 4, see Table 3.

5. August 18-19, six batches of eggs were experimented with. Results obtained from batches nos. 1-3 are given in Publ. Seto Mar. Biol. Lab., vol. 18, no. 6, p. 389, Table 4; as to the results gained from batches nos. 4-6, see Table 4 .

IV. Autumn season, two experiments were made in October and November, with eggs of Pseudocentrotus depressus (A. Agassiz).

1. October 20-21, in the very early time of the spawning season, see Table 5.

2. November $28-29$, see Table 6.

(Notes common to all tables: "Time of observation*" shows the time after insemination; No. 1 to No. 6 are batch numbers of eggs; the maturing states of gonads are given as nearly ripe $+(+)$, ripe ++ , nearly full ripe $++(+)$, full ripe +++ .)

NAOMASA KOBAYASHI

Table 1. Results of the June 6 and 7 experiment with eggs of Anthocidaris crassispina. Wind: S 1. Test water temperature: $22^{\circ} \mathrm{G}$

\begin{tabular}{|c|c|c|c|c|c|c|c|}
\hline \multirow{2}{*}{$\begin{array}{l}\text { Indicatory } \\
\text { states }\end{array}$} & \multirow{2}{*}{$\begin{array}{l}\text { Time of } \\
\text { observation* }\end{array}$} & \multicolumn{2}{|c|}{$\begin{array}{l}\text { Running sea } \\
\text { water of } \\
\text { laboratory }\end{array}$} & \multicolumn{2}{|c|}{$\begin{array}{l}\text { Water from } \\
\text { open sea side of } \\
\text { Hatakejima }\end{array}$} & \multicolumn{2}{|c|}{$\begin{array}{l}\text { Water from } \\
\text { land side of } \\
\text { Hatakejima }\end{array}$} \\
\hline & & $\begin{array}{l}\text { No. } 1 \\
++t\end{array}$ & $\begin{array}{l}\text { No. } 2 \\
++t\end{array}$ & No. 1 & No. 2 & No. 1 & No. 2 \\
\hline $\begin{array}{l}\text { formation of } \\
\text { fertilization } \\
\text { membrane }\end{array}$ & $\begin{array}{l}\text { hr. min. } \\
0: 03\end{array}$ & 99.4 & $99.2^{\%}$ & 87.8 & $98.0^{\%}$ & 71.6 & $92.2^{\%}$ \\
\hline one cell & \multirow{3}{*}{$1: 15$} & 2.1 & 0.8 & 15.1 & 2.4 & 30.2 & 7.7 \\
\hline two cells & & 97.8 & 99.1 & 84.3 & 97.2 & 69.0 & 90.1 \\
\hline $\begin{array}{l}\text { multi-cells } \\
\text { (polyspermy) }\end{array}$ & & 0.1 & 0.1 & 0.6 & 0.4 & 0.8 & 2.2 \\
\hline $\begin{array}{l}\text { permanent } \\
\text { blastula }\end{array}$ & \multirow{3}{*}{$24: 00$} & 4.6 & 1.2 & 5.4 & 1.4 & 10.4 & 2.3 \\
\hline gastrula & & 95.2 & 98.8 & 94.4 & 98.6 & 89.1 & 97.6 \\
\hline exogastrula & & 0.2 & 0.0 & 0.2 & 0.0 & 0.5 & 0.1 \\
\hline
\end{tabular}

\footnotetext{
Publ. Seto Mar, Biol, Lab., XVIII, 421-424, 1971. (Biological data 2)
} 
Table 2. Results of the July 17 experiment with eggs of Anthocidaris crassispina. Wind: S 1 . Test water temperature: $28^{\circ} \mathrm{C}$.

\begin{tabular}{|c|c|c|c|c|c|c|c|c|c|c|}
\hline \multirow{2}{*}{ Indicatory states } & \multirow{2}{*}{$\begin{array}{l}\text { Time of observ- } \\
\text { ation* }\end{array}$} & \multicolumn{3}{|c|}{$\begin{array}{l}\text { Running sea water of } \\
\text { laboratory }\end{array}$} & \multicolumn{3}{|c|}{$\begin{array}{l}\text { Water from oepn sea side } \\
\text { of Hatakejima }\end{array}$} & \multicolumn{3}{|c|}{$\begin{array}{l}\text { Water from land side of } \\
\text { Hatakejima }\end{array}$} \\
\hline & & $\begin{array}{c}\text { No. } 1 \\
++\end{array}$ & $\begin{array}{l}\text { No. } 2 \\
+++\end{array}$ & $\begin{array}{l}\text { No. } 3 \\
+++\end{array}$ & No. 1 & No. 2 & No. 3 & No. 1 & No. 2 & No. 3 \\
\hline $\begin{array}{l}\text { formation of } \\
\text { fertilization } \\
\text { membrane }\end{array}$ & $\begin{array}{c}\text { hr. min. } \\
0: 03\end{array}$ & 98.8 & 99.4 & $99.3^{\%}$ & 98.6 & $99.4^{\%}$ & 99.1 & 97.8 & 99.6 & $99.2^{\%}$ \\
\hline one cell & \multirow{3}{*}{$0: 45$} & 2.1 & 1.1 & 1.2 & 3.4 & 2.1 & 1.6 & 5.4 & 3.4 & 1.4 \\
\hline two cells & & 96.4 & 98.7 & 98.5 & 95.2 & 96.8 & 97.3 & 92.4 & 95.4 & 97.6 \\
\hline $\begin{array}{l}\text { multi-cells } \\
\text { (polyspermy) }\end{array}$ & & 1.5 & 0.2 & 0.3 & 1.4 & 1.1 & 1.1 & 2.2 & 1.2 & 1.0 \\
\hline $\begin{array}{l}\text { permanent } \\
\text { blastula }\end{array}$ & \multirow{3}{*}{$12: 00$} & 0.7 & 0.5 & 0.7 & 0.8 & 0.7 & 0.5 & 0.8 & 0.5 & 0.7 \\
\hline gastrula & & 99.3 & 99.4 & 99.0 & 99.2 & 99.3 & 99.4 & 99.2 & 99.1 & 99.1 \\
\hline exogastrula & & 0.0 & 0.1 & 0.3 & 0.0 & 0.0 & 0.1 & 0.0 & 0.4 & 0,2 \\
\hline
\end{tabular}

Table 3. Results of the August 4 experiment with eggs of Anthocidaris crassispina. Wind: SW 1. Test water temperature: $28.5^{\circ} \mathrm{G}$.

\begin{tabular}{|c|c|c|c|c|c|c|c|c|c|c|c|c|c|}
\hline \multirow{2}{*}{$\begin{array}{l}\text { Indicatory } \\
\text { states }\end{array}$} & \multirow{2}{*}{$\begin{array}{l}\text { Time of } \\
\text { observation* }\end{array}$} & \multicolumn{3}{|c|}{$\begin{array}{l}\text { Running sea water of } \\
\text { laborzatory }\end{array}$} & \multicolumn{3}{|c|}{$\begin{array}{l}\text { Water from open sea } \\
\text { side of Hatakejima }\end{array}$} & \multicolumn{3}{|c|}{$\begin{array}{l}\text { Water from land side } \\
\text { of Hatakejima }\end{array}$} & \multicolumn{3}{|c|}{$\begin{array}{l}\text { Sea water from } \\
\text { Tsunashirazu cove }\end{array}$} \\
\hline & & $\begin{array}{l}\text { No. } 1 \\
+++\end{array}$ & $\begin{array}{r}\text { No. } 2 \\
++(+)\end{array}$ & $\begin{array}{c}\text { No. } 3 \\
++\end{array}$ & No. 1 & No. 2 & No. 3 & No. 1 & No. 2 & No. 3 & No. 1 & No. 2 & No. 3 \\
\hline formation of & hr. min. & $\%$ & $\%$ & $\%$ & $\%$ & $\%$ & $\%$ & $\%$ & $\%$ & $\%$ & $\%$ & $\%$ & $\%$ \\
\hline $\begin{array}{l}\text { fertilization } \\
\text { membrane }\end{array}$ & $0: 03$ & 99.8 & 98.2 & 98.6 & 99.7 & 98.5 & 98.3 & 99.6 & 98.0 & 95.1 & 98.8 & 98.2 & 95.0 \\
\hline one cell & \multirow{3}{*}{$0: 45$} & 9.4 & 32.4 & 12.4 & 7.6 & 32.6 & 13.5 & 12.3 & 40.2 & 20.8 & 15.3 & 41.0 & 20.9 \\
\hline two cells & & 90.0 & 67.2 & 87.1 & 91.9 & 66.7 & 85.9 & 87.2 & 58.5 & 77.6 & 83.8 & 57.8 & 75.3 \\
\hline $\begin{array}{l}\text { multi-cells } \\
\text { (polyspermy) }\end{array}$ & & 0.6 & 0.4 & 0.5 & 0.5 & 0.7 & 0.6 & 0.5 & 1.3 & 1.6 & 0.9 & 1.2 & 3.8 \\
\hline $\begin{array}{l}\text { permanent } \\
\text { blastula }\end{array}$ & \multirow{3}{*}{$10: 00$} & 1.8 & 1.8 & 1.7 & 1.5 & 1.6 & 1.4 & 2.3 & 3.6 & 2.2 & 2.2 & 2.1 & 3.3 \\
\hline gastrula & & 98.2 & 98.1 & 98.3 & 98.5 & 98.3 & 98.5 & 97.6 & 96.1 & 97.3 & 97.4 & 97.3 & 96.3 \\
\hline exogastrula & & 0.0 & 0.1 & 0.0 & 0.0 & 0.1 & 0.1 & 0.1 & 0.3 & 0.5 & 0.4 & 0.6 & 0.4 \\
\hline
\end{tabular}


Table 4. Results of the Aug. 18 and 19 experiment with eggs of Anthocidaris crassispina. Wind: 0. Test water temperature: $28^{\circ} \mathrm{C}$.

\begin{tabular}{|c|c|c|c|c|c|c|c|c|c|c|c|c|c|}
\hline \multirow{2}{*}{$\begin{array}{l}\text { Indicatory } \\
\text { states }\end{array}$} & \multirow{2}{*}{$\begin{array}{l}\text { Time of } \\
\text { observation* }\end{array}$} & \multicolumn{3}{|c|}{$\begin{array}{l}\text { Running sea water of } \\
\text { laboratory }\end{array}$} & \multicolumn{3}{|c|}{$\begin{array}{l}\text { Water from open sea } \\
\text { side of Hatakejima }\end{array}$} & \multicolumn{3}{|c|}{$\begin{array}{l}\text { Water from land side } \\
\text { of Hatakejima }\end{array}$} & \multicolumn{3}{|c|}{$\begin{array}{l}\text { Sea water from } \\
\text { Tsunashirazu cove }\end{array}$} \\
\hline & & $\begin{array}{l}\text { No. } 4 \\
+(+)\end{array}$ & $\begin{array}{c}\text { No. } 5 \\
++\end{array}$ & $\begin{array}{c}\text { No. } 6 \\
++(t)\end{array}$ & No. 4 & No. 5 & No. 6 & No. 4 & No. 5 & No. 6 & No. 4 & No. 5 & No. 6 \\
\hline formation of & hr. min. & $\%$ & $\%$ & $\%$ & $\%$ & $\%$ & $\%$ & $\%$ & $\%$ & $\%$ & $\%$ & $\%$ & $\%$ \\
\hline $\begin{array}{l}\text { fertilization } \\
\text { membrane }\end{array}$ & $0: 03$ & 85.7 & 89.8 & 85.3 & 80.3 & 87.9 & 78.9 & 73.5 & 85.2 & 61.2 & 68.2 & 82.3 & 62.3 \\
\hline one cell & \multirow{3}{*}{$0: 45$} & 19.7 & 13.2 & 21.5 & 26.6 & 14.2 & 27.5 & 36.2 & 19.6 & 41.2 & 45.6 & 22.4 & 38.2 \\
\hline two cells & & 80.2 & 86.6 & 78.4 & 73.2 & 85.5 & 72.3 & 63.4 & 80.0 & 58.1 & 53.6 & 76.9 & 61.0 \\
\hline $\begin{array}{l}\text { multi-ceils } \\
\text { (polyspermy) }\end{array}$ & & 0.1 & 0.2 & 0.1 & 0.2 & 0.3 & 0.2 & 0.4 & 0.4 & 0.7 & 0.8 & 0.7 & 0.8 \\
\hline $\begin{array}{l}\text { permanent } \\
\text { blastula }\end{array}$ & \multirow{3}{*}{$12: 00$} & 0.7 & 0.6 & 0.9 & 0.8 & 0.6 & 0.7 & 0.9 & 0.9 & 1.2 & 0.9 & 1.3 & 1.4 \\
\hline gastrula & & 99.3 & 99.3 & 99.0 & 99.2 & 99.3 & 99.3 & 99.0 & 99.0 & 98.6 & 98.9 & 98.5 & 98.3 \\
\hline exogastrula & & 0.0 & 0.1 & 0.1 & 0.0 & 0.1 & 0.0 & 0.1 & 0.1 & 0.2 & 0.2 & 0.2 & 0.3 \\
\hline
\end{tabular}

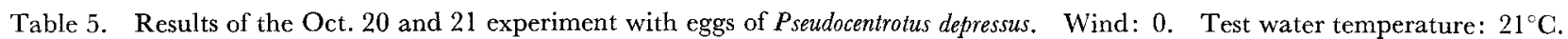

\begin{tabular}{|c|c|c|c|c|c|c|c|c|c|}
\hline \multirow{2}{*}{ Indicatory states } & \multirow{2}{*}{$\begin{array}{l}\text { Time of } \\
\text { observation* }\end{array}$} & \multicolumn{2}{|c|}{$\begin{array}{l}\text { Running sea water of } \\
\text { laboratory }\end{array}$} & \multicolumn{2}{|c|}{$\begin{array}{l}\text { Water from open sea } \\
\text { side of Hatakejima }\end{array}$} & \multicolumn{2}{|c|}{$\begin{array}{l}\text { Water from land side } \\
\text { of Hatakejima }\end{array}$} & \multicolumn{2}{|c|}{$\begin{array}{l}\text { Sea water from } \\
\text { Tsunashirazu cove }\end{array}$} \\
\hline & & $\begin{array}{l}\text { No. } 1 \\
++t\end{array}$ & $\begin{array}{l}\text { No. } 2 \\
+(+)\end{array}$ & No. 1 & No. 2 & No. 1 & No. 2 & No. 1 & No. 2 \\
\hline $\begin{array}{l}\text { formation of } \\
\text { fertilization } \\
\text { membrane }\end{array}$ & $\begin{array}{c}\text { hr. min. } \\
0: 03\end{array}$ & 93.2 & $82.1^{\%}$ & $93.4^{\%}$ & $83.0^{\%}$ & 92.8 & 80.8 & $90.2^{\%}$ & $80.1^{\%}$ \\
\hline one cell & \multirow{3}{*}{$1: 30$} & 7.5 & 20.1 & 7.1 & 20.3 & 8.6 & 21.3 & 10.4 & 22.6 \\
\hline two cells & & 92.4 & 79.6 & 92.7 & 79.5 & 91.2 & 78.5 & 86.1 & 77.1 \\
\hline $\begin{array}{l}\text { multi-cells } \\
\text { (polyspermy) }\end{array}$ & & 0.1 & 0.3 & 0.2 & 0.2 & 0.2 & 0.2 & 3.5 & 0.3 \\
\hline $\begin{array}{l}\text { permanent } \\
\text { blastula }\end{array}$ & \multirow{3}{*}{$19: 00$} & 0.3 & 0.2 & 0.2 & 0.3 & 0.4 & 0.3 & 0.7 & 0.4 \\
\hline gastrula & & 99.7 & 99.8 & 99.8 & 99.7 & 99.5 & 99.7 & 99.0 & 99.5 \\
\hline exogastrula & & 0.0 & 0.0 & 0.0 & 0.0 & 0.1 & 0.0 & 0.3 & 0.1 \\
\hline
\end{tabular}


Table 6. Results of the Nov. 28 and 29 experiment with eggs of Pseudocentrolus depressus. Wind: $\mathrm{N} 1$. Test water temperature: $16.5^{\circ} \mathrm{C}$.

\begin{tabular}{|c|c|c|c|c|c|c|c|c|c|c|c|c|c|}
\hline \multirow{2}{*}{$\begin{array}{l}\text { Indicatory } \\
\text { states }\end{array}$} & \multirow{2}{*}{$\begin{array}{l}\text { Time of } \\
\text { observation* }\end{array}$} & \multicolumn{3}{|c|}{$\begin{array}{l}\text { Running sea water of } \\
\text { laboratory }\end{array}$} & \multicolumn{3}{|c|}{$\begin{array}{l}\text { Water from open sea } \\
\text { side of Hatakejima }\end{array}$} & \multicolumn{3}{|c|}{$\begin{array}{l}\text { Water from land side } \\
\text { of Hatakejima }\end{array}$} & \multicolumn{3}{|c|}{$\begin{array}{l}\text { Sea water from } \\
\text { Tsunashirazu cove }\end{array}$} \\
\hline & & $\begin{array}{l}\text { No. } 1 \\
+++\end{array}$ & $\begin{array}{l}\text { No. } 2 \\
+++\end{array}$ & $\begin{array}{l}\text { No. } 3 \\
++\end{array}$ & No. 1 & No. 2 & No. 3 & No. 1 & No. 2 & No. 3 & No. 1 & No. 2 & No. 3 \\
\hline $\begin{array}{l}\text { formation of } \\
\text { fertilization } \\
\text { membrane }\end{array}$ & $\begin{array}{c}\text { hr. min. } \\
0: 03\end{array}$ & 98.9 & $84.7^{\%}$ & 85.7 & $98.7^{\%}$ & 84.5 & $86.1 \%$ & $96.7^{\%}$ & $83.1 \%$ & $85.1 \%$ & $92.2^{\%}$ & 82.3 & $82.6^{\%}$ \\
\hline one cell & \multirow{3}{*}{$2: 00$} & 3.1 & 17.6 & 16.4 & 3.2 & 18.1 & 15.3 & 5.4 & 19.2 & 17.3 & 6.8 & 22.1 & 19.4 \\
\hline two cells & & 96.9 & 82.4 & 83.5 & 96.7 & 81.9 & 84.5 & 94.4 & 79.5 & 82.2 & 91.4 & 76.0 & 79.3 \\
\hline $\begin{array}{l}\text { multi-cells } \\
\text { (polyspermy) }\end{array}$ & & 0.0 & 0.0 & 0.1 & 0.1 & 0.0 & 0.2 & 0.2 & 1.3 & 0.5 & 1.8 & 1.9 & 1.3 \\
\hline $\begin{array}{l}\text { permanent } \\
\text { blastula }\end{array}$ & \multirow{3}{*}{$32: 00$} & 4.3 & 4.5 & 4.7 & 4.1 & 4.3 & 4.9 & 5.2 & 5.8 & 5.9 & 5.9 & 7.9 & 8.1 \\
\hline gastrula & & 95.7 & 95.4 & 95.3 & 95.8 & 95.7 & 94.9 & 94.6 & 94.1 & 93.7 & 93.8 & 91.7 & 91.7 \\
\hline exogastrula & & 0.0 & 0.1 & 0.0 & 0.1 & 0.0 & 0.2 & 0.2 & 0.1 & 0.4 & 0.3 & 0.4 & 0.2 \\
\hline
\end{tabular}

